\title{
Strengthening eHealth Systems to Support Universal Health Coverage in sub-Saharan Africa
}

\author{
Adebowale Ojo ${ }^{1,2} *$, Herman Tolentino', Steven S. Yoon ${ }^{1}$ \\ ${ }^{1}$ Division of Global HIV and TB, Centers for Disease Control and Prevention, Atlanta, GA \\ ${ }^{2}$ Public Health Informatics Fellowship Program, Division of Scientific Education and Professional \\ Development, Center for Surveillance, Epidemiology, and Laboratory Services, Centers for Disease \\ Control and Prevention, Atlanta, GA
}

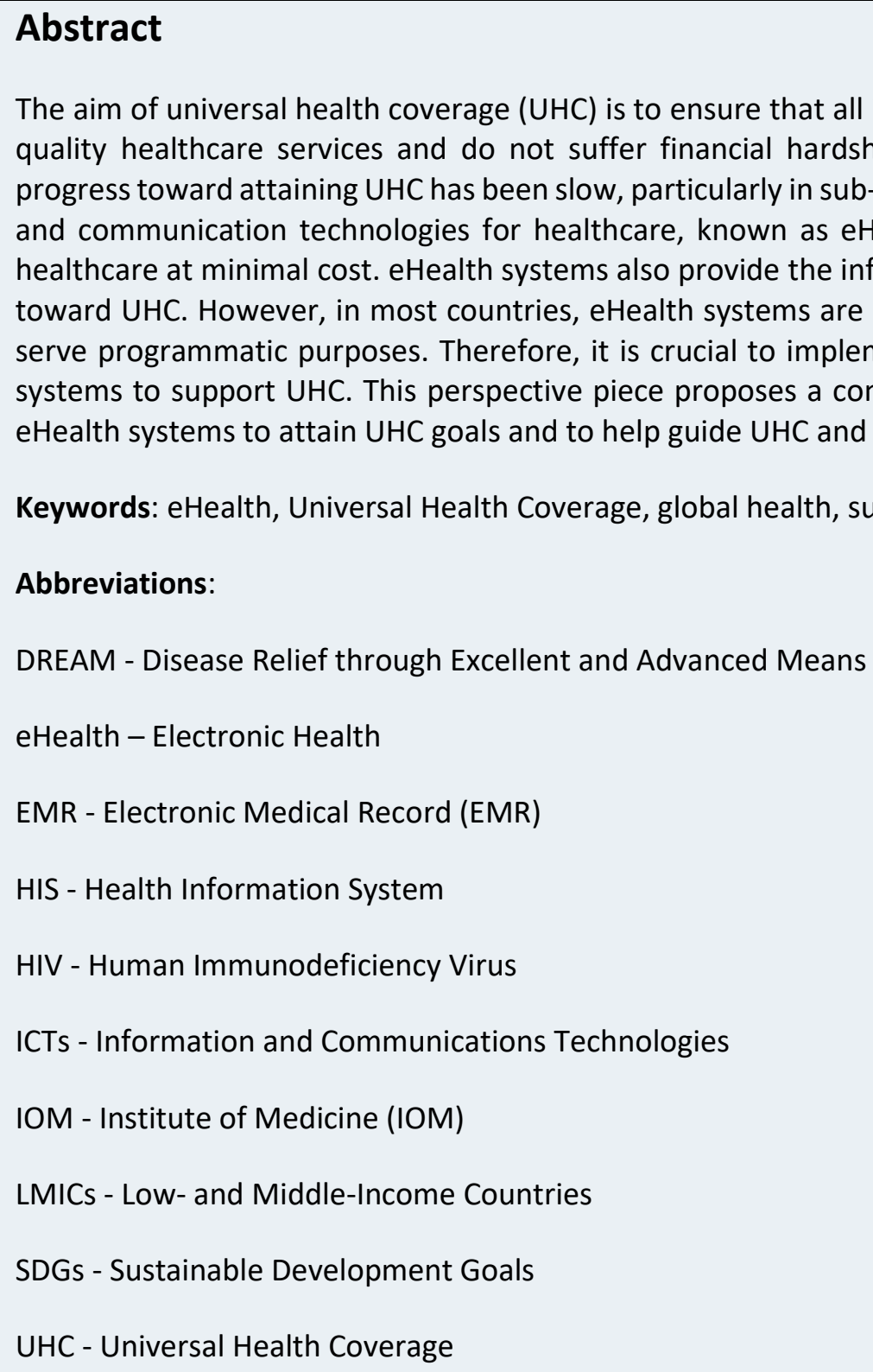

The aim of universal health coverage (UHC) is to ensure that all individuals in a country have access to quality healthcare services and do not suffer financial hardship in using these services. However, progress toward attaining UHC has been slow, particularly in sub-Saharan Africa. The use of information and communication technologies for healthcare, known as eHealth, can facilitate access to quality healthcare at minimal cost. eHealth systems also provide the information needed to monitor progress toward UHC. However, in most countries, eHealth systems are sometimes non-functional and do not serve programmatic purposes. Therefore, it is crucial to implement strategies to strengthen eHealth systems to support UHC. This perspective piece proposes a conceptual framework for strengthening eHealth systems to attain UHC goals and to help guide UHC and eHealth strategy development.

Keywords: eHealth, Universal Health Coverage, global health, sub-Saharan Africa 


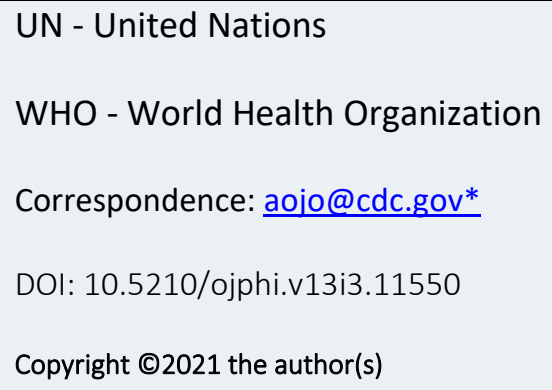

\section{Introduction}

At the 2015 United Nations (UN) General Assembly, member countries agreed upon 17 Sustainable Development Goals (SDGs), including SDG 3.8, with the target of achieving universal health coverage (UHC) by 2030. UHC includes financial risk protection, access to quality essential healthcare services, and access to safe, effective, high-quality, and affordable essential medicines and vaccines for all. Since the Alma-Ata Declaration of 1978, the World Health Organization (WHO) has promoted health for all, meaning that individuals should have an acceptable level of health that allows for social and economic productivity [1]. WHO has continued to encourage national governments to achieve UHC [2,3], defined as ensuring "all people receive the quality health services they need without suffering financial hardship" [4].

According to a $2017 \mathrm{WHO}$ and World Bank report on UHC global monitoring [5], progress toward UHC has been considerably slow, particularly in sub-Saharan Africa. As noted in the report, globally, $50 \%$ of people do not have access to essential healthcare, and each year, out-of-pocket healthcare expenses lead to extreme poverty for approximately 100 million people. Similarly, the WHO computes a UHC service coverage index to indicate a country's progress towards coverage for essential health services and financial protection for their population [6]. The index score is derived using the average of 14 indicators and reported on a scale of 0 to 100, indicating a low to a high level of UHC service coverage. As shown in Figure 1, the map of African countries shows that most of the countries have an index score of less than 50 .

Strengthening national healthcare systems is a critical step toward UHC. This includes robust financing structures and processes that spread financial risk across a population and that measures risk protection gaps and outcomes; integrated, people-centered healthcare services; adequate numbers of healthcare workers with the expertise to deliver these services; investments in programs that develop this workforce; good governance; supply chain systems for procuring, tracking, distributing, and delivering quality medicines and other interventions; and wellfunctioning, scalable, and interoperable health and related information systems. Aside from improving these services, UHC also focuses on how these components are funded, managed, and delivered. 
WHO notes that achieving UHC is difficult without the support of eHealth [7], defined as the "cost-effective and secure use of information and communications technologies (ICTs) for health and health-related fields, including healthcare services, health surveillance, health literature, and health education, knowledge and research [8]." eHealth can solve or prevent health problems, improve access to healthcare systems and services, and improve health outcomes [9]. In line with UHC objectives, eHealth has the potential to improve access and quality of care, expand coverage, minimize the cost of accessing healthcare, enable connectivity in healthcare systems, and build healthcare capacity [10-12]. Via interoperable health information systems (HIS), eHealth can provide the information needed to ensure accountability and to monitor progress toward UHC goals $[13,14]$. As such, WHO member countries have agreed on the importance of eHealth for strengthening healthcare systems and attaining UHC [15].

However, the design, development, and implementation of eHealth systems are not without challenges. For instance, most eHealth systems in low- and middle-income countries (LMICs) are not yet scalable and sustainable $[16,17]$. Challenges include policy and governance, financing, the use of standards, and workforce capacity. Similarly, the WHO [7] conducted a global survey on eHealth development and their role in achieving UHC. The report, published in 2016, showed the state of development on different components of eHealth across WHO member countries. A variable of interest is the availability of a national electronic health record (EHR) system, a possible indicator of the extent of a country's population covered by eHealth. Findings from the survey, as depicted in Figure 2, show that only five out of the 33 Africa countries surveyed have a national electronic health record (EHR) system.

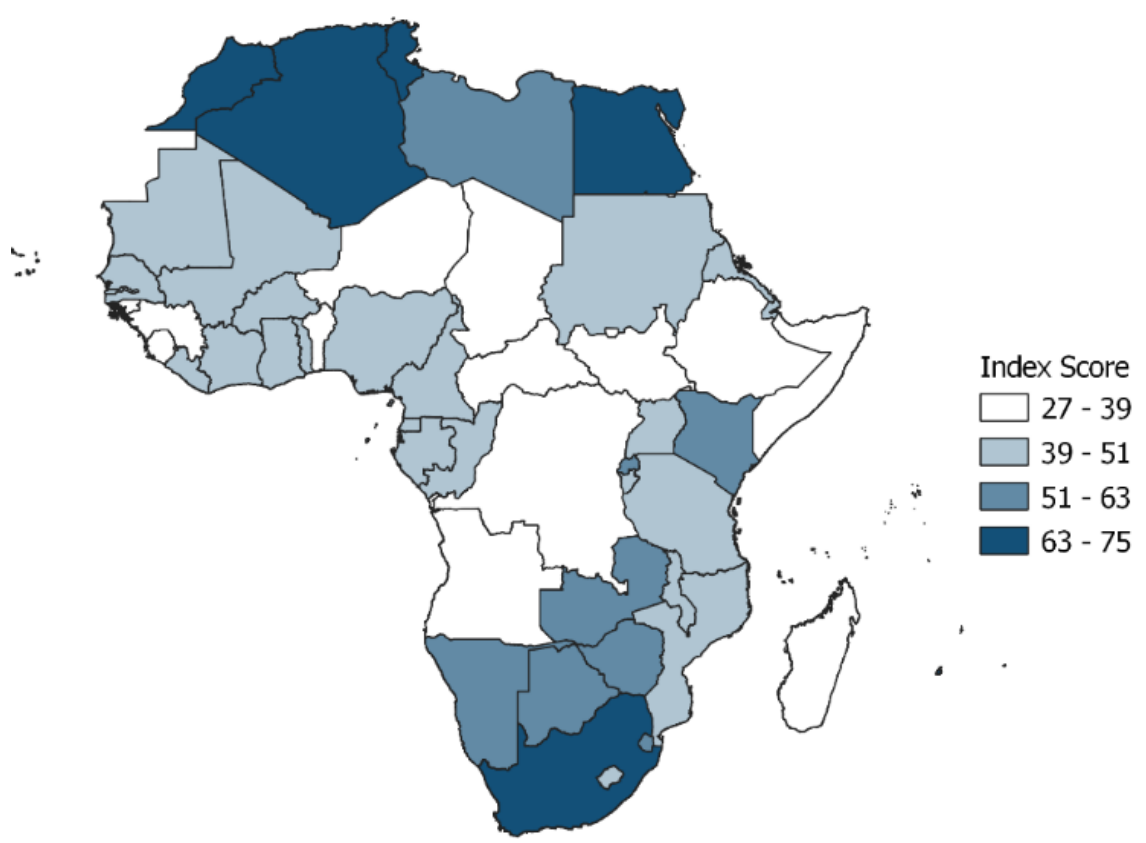

Figure 1: UHC Service Coverage Index in Africa (Data Source: WHO [6]) 


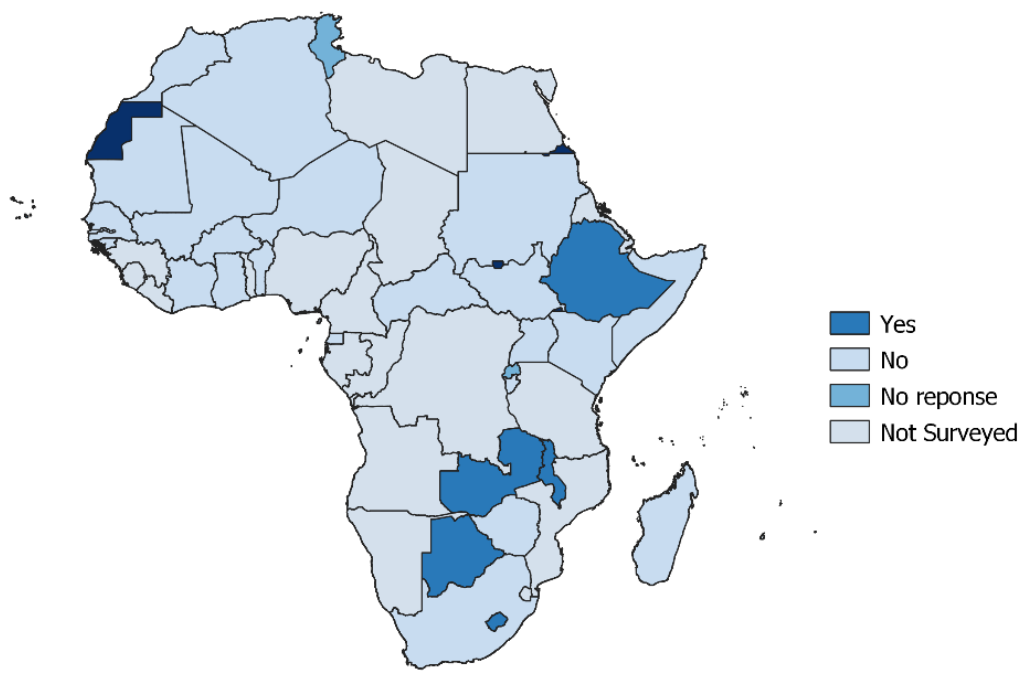

Figure 2: Availability of a National Electronic Health Record (EHR) System in Africa (Data Source: WHO [7])

We argue that strengthening eHealth systems can accelerate progress toward UHC goals. Therefore, we propose a conceptual model for strategically strengthening eHealth systems to improve UHC outcomes. We describe potential eHealth interventions that could help attain UHC outcomes; important foundational elements necessary for strengthening eHealth systems; and the proposed conceptual model.

\section{eHealth Interventions and UHC Outcomes}

In measuring progress toward achieving UHC, it is important to capture healthcare system coverage, including the number of people receiving care and the availability and quality of essential healthcare services. Data on household healthcare expenditure and the proportion of household income used for healthcare are also important.

WHO has recognized the role of eHealth in supporting the UHC outcome of ensuring quality healthcare services that cover all persons [9,18]. Similarly, in the United States, Buntin et al. [19] highlighted the potential contributions of the provisions of the Health Information Technology for Economic and Clinical Health Act to achieving the objectives of the Affordable Care Act. For instance, it was noted that the use of health information technology by service providers for individual-level information management could contribute to efforts aimed at quality improvement, cost reduction, and increased access and coverage.

In line with the WHO digital health interventions classification [20], we examined the potential of stakeholder-driven eHealth interventions as a means to attaining UHC outcomes. 


\section{Quality of healthcare services}

Access to quality healthcare services is one of the fundamental tenets of UHC. A publication of the US Institute of Medicine (IOM) noted that although the number of people with access to healthcare services worldwide is increasing, these services are often of poor quality [21].

According to IOM, the six key dimensions to measuring the quality of healthcare services are safety, efficiency, person-centeredness, timeliness/accessibility, effectiveness, and equity [21]. Interestingly, some of these dimensions are also embedded in the access and coverage and financial risk protection dimensions of UHC, which are discussed below.

Accurate and timely information is needed to measure quality and contribute to quality improvement efforts. eHealth interventions such as health management information systems and health information repositories provide both individual-level and aggregate data that could facilitate quality improvement at different levels of healthcare [19]. Specifically, for measures such as patient safety and efficiency, electronic medical record (EMR) systems are used for managing patients' clinical and laboratory information over time and space. Thus, EMRs have the potential to improve patient care and safety and also reduce waste associated with duplicate diagnostic tests, leading to efficiency [19]. Similarly, studies have shown the potential of telemedicine in improving safety, especially by reducing medication errors and malpractice claims and costs [22,23].

\section{Access and coverage}

Tanahashi model and UHC. Another key dimension of UHC is that all persons can access necessary healthcare services. Drawing from the widely cited Tanahashi model of health service coverage [24], five key measures of healthcare access and coverage are availability coverage, accessibility coverage, acceptability coverage, contact coverage, and effective coverage. These measures are represented as cascades of successive levels in which challenges at one level affect the next, thus creating healthcare system performance gaps in quality, coverage, and affordability. Mehl and Labrique [25] adapted the Tanahashi model to UHC and updated these measures to include accountability coverage, availability of commodities and equipment, availability of human resources, continuous coverage, and financial coverage. The updated model also served as the basis of the WHO recommendations for digital health interventions for healthcare systems [18].

Accountability coverage. A fundamental tenet of UHC is the ability to account for all individuals that need access to healthcare services. Accountability coverage means being able to quantify the population enrolled in the healthcare system. To achieve this and promote person-centered care, eHealth systems enable countries to monitor an individual's health across time and place, that is, including birth, key health events, and death. eHealth systems such as EMRs, identification registries, civil registration and vital statistics, and health information repositories, can capture data needed to determine accountability coverage. For example, biometric data via fingerprint identification have been used to link community data and hospitals to uniquely identify individuals seeking care in two district hospitals in Ghana [26].

Accessibility of healthcare facilities, availability of commodities and equipment, and availability of human resources. To achieve the UHC objective of quality healthcare services, healthcare facilities need sufficient qualified and motivated workers and accessible essential commodities 
and equipment. eHealth systems, such as telemedicine and client communication systems, can be used to remove barriers that may prevent individuals from accessing healthcare services. Telemedicine has been used to bring healthcare services to hard-to-reach populations and enhance learning in instances of insufficient expertise [27,28]. For example, the Disease Relief through Excellent and Advanced Means (DREAM) program operating in sub-Saharan Africa [29] has used telemedicine to improve the knowledge of local healthcare workers in treating neurological disorders in patients with HIV. Furthermore, human resource information systems have been used to deliver interventions addressing healthcare worker shortages, training, and regulatory concerns in Kenya and Zambia [30]. Logistics management information systems, such as cStock in Malawi, have been used for reporting stock data, thereby enhancing supply chain management [31].

Contact coverage and continuous coverage. In the context of equity in healthcare service access, contact coverage is the number of individuals who are in contact with the needed service. Continuous coverage, on the other hand, is the extent to which those in contact with a needed service can complete the full course of intervention required. Barriers such as affordability, negative experiences with a care provider, and social discrimination may affect individuals' demand for healthcare services, thus affecting coverage. To improve the demand for healthcare services, client communication systems can enhance interaction between clients and providers. EMRs and shared health records or health data repositories can ensure continuity of care and allow for longitudinal tracking of patients. For example, studies have shown that the use of text messages for patient education, appointment and medication reminders, and integration of laboratory results with medical records improved maternal retention and antiretroviral therapy adherence among HIV-positive pregnant women [32].

Effective coverage. Effective coverage refers to the number of individuals in need of healthcare services who receive quality and satisfactory services. Sometimes, healthcare providers' inefficiencies may contribute to patients' dissatisfaction with healthcare services, thus leading to reduced effective coverage. As noted earlier, telemedicine interventions could serve as a learning and collaboration platform for healthcare providers. Furthermore, the use of decision support systems can improve providers' knowledge of evidence-based best practices and increase their efficiency and effectiveness. For example, in South Africa, primary care clinicians use a checklistbased decision support tool for common health conditions [33]. Similarly, a study assessing a decision support system for disease surveillance in Sierra Leone reported that the system aided decision making for operational tasks while also reducing the time spent on data analysis [34].

Financial coverage. A key objective of UHC is to ensure that the cost of using healthcare services does not put people at risk for financial hardship. One of the performance measures is the number of individuals protected from poverty due to receiving healthcare services. This implies that there are healthcare financing mechanisms in place to ensure effective and efficient service delivery while minimizing costs to patients. Healthcare finance and insurance information systems can deliver interventions that encourage clients to seek healthcare services and providers to perform them. Similarly, such systems also facilitate managing health insurance issues such as membership enrollment and verification, and claims management. For example, in Kenya, studies have shown how M-TIBA (http://m-tiba.co.ke), a mobile health application, helps families save money for future healthcare costs [35]. 


\section{eHealth Foundations}

Most LMICs struggling toward UHC also face challenges related to eHealth policy implementation, leadership, funding, infrastructure, and workforce capacity [16,17]. For example, investments and funding required for complex interoperable HIS design, development, implementation, and use are not readily available and sustainable in the long term. Simultaneously, the benefits of large investments in HIS are often not readily visible in the short term. Similarly, gaps in economic evaluation can hinder continued financial investments in eHealth projects [36]. Furthermore, countries often lack the informatics workforce capacity needed to design, develop, implement, and effectively use eHealth [10]. Finally, most countries lack a national-scale eHealth infrastructure, which hinders interoperability needed for linking disparate HIS [11]. We adapt the informatics-savvy health department framework [37] to conceptualize what is needed to optimize eHealth systems to help achieve UHC.

The informatics-savvy health department framework was developed as a call for health departments to implement measures needed for evolving information needs. An informatics-savvy health department or ministry has "a clear vision, strategy, and governance for information management and use; a workforce skilled in using information and information technologies; and well-designed and effectively used information systems" [37]. Thus, the framework is comprised of three main elements: vision and strategy, competent workforce, and well-designed information systems. We add eHealth financing as a distinct element to be considered as part of the eHealth foundations. While one may argue that eHealth financing is already a component of vision and strategy, we posit that financing is a crucial factor to be considered in strengthening eHealth systems, particularly in sub-Saharan Africa, where lack of funds has often been cited as a major sustainability challenge $[38,39]$.

\section{Vision and Strategy}

A vision statement and strategy can help position eHealth to support UHC. This addresses a fundamental and pervasive challenge of eHealth projects that have been unable to reach scale in most countries. Key issues such as an existing national eHealth strategy, knowledgeable leadership, sustained funding, and strong information partnerships are important indicators of vision and strategy. A national eHealth strategy helps coordinate eHealth activities in a country and should reflect the country's eHealth vision, action plan, and monitoring and evaluation plan [40]. eHealth strategies facilitate the development and adoption of standards for interoperability, and the required regulations needed for the eHealth ecosystem to thrive. Although some countries have developed an eHealth strategy, there is still scarce evidence of implementation and outcomes. Similarly, leadership is fundamental to driving strategy and implementation actions. Knowledgeable, decisive, and supportive leaders are crucial to implementing change, establishing and sustaining partnerships, and motivating the workforce toward the realization of a country's eHealth goals [16,41,42]. Considering the diverse stakeholders involved in planning and implementing eHealth projects, it is important to develop strong information partnerships to align the country's eHealth goals. 


\section{eHealth Financing}

Integral to the successful implementation and sustainability of eHealth interventions is balanced eHealth financing approaches, including short-term and long-term funding, enterprise funding, and programmatic funding from internal and external sources. The implementation of eHealth systems requires significant capital investment at the outset. Also, maintenance and sustainability of eHealth systems require continuous funding, which could be justified by quantitative and nonquantitative articulation of benefits - capacities usually scarce in low-resource settings. Abu Taher et al. [43] revised the Tsuji-Akematsu model of quantifying eHealth benefits to propose that if the cost of using eHealth system could be quantified for each user, these calculations could be used to indicate a revenue source for financing eHealth systems. For instance, in a system where health is financed through users' contribution, the cost of using eHealth systems, when known, could also be added to the cost of using healthcare. Given potential, systematic, and eHealth-enabled percapita quantification of costs and benefits of eHealth interventions, we posit that healthcare financing models adopted by countries to support UHC could also be applied to financing eHealth.

\section{Competent Workforce}

Studies have shown that the eHealth workforce in sub-Saharan Africa is insufficient, with some countries even lacking the skills needed to drive eHealth initiatives [41,44]. The eHealth workforce is expected to be able to "discriminate vast amounts of information and extract and synthesize knowledge that is necessary for clinical and population-based decision making" [45]. Strategies are needed to motivate the existing workforce to improve their knowledge and skills and to teach these healthcare workers. Similarly, strategies that align with eHealth goals are needed to recruit and retain healthcare workers. Lastly, training institutions can develop and strengthen academic programs in health information and communications technologies to ensure the continuous availability of a well-trained workforce.

\section{Well-Designed eHealth Architecture}

The importance of a well-designed eHealth architecture cannot be overemphasized. Linking disparate information systems is critical for the accountability objective of UHC. A key indicator is an eHealth enterprise architecture that establishes the various data sources required by the country's healthcare sector and addresses interoperability, data standards, security and confidentiality, and information systems (software, hardware, and infrastructure) issues. This, in addition to plans documented in a national eHealth strategy, can guide a country toward attaining eHealth goals [46].

\section{Conceptual Model}

We propose a framework for strengthening eHealth systems to support UHC outcomes and to help guide joint UHC and eHealth strategic planning (Figure 3). Our conceptual model is a logic model with three main components: eHealth foundations, stakeholder-driven eHealth interventions, and UHC outcomes.

eHealth foundations, as adapted from the informatics-savvy health department framework, consist of vision and strategy, competent workforce, well-designed eHealth architecture, and financing. 
These interrelated foundational elements, as shown in the model, enable the effective design, development, and implementation of eHealth interventions.

The second component of the model, stakeholder-driven eHealth interventions, is derived from WHO's classification of digital health interventions, which is an effort to create a taxonomy of the digital and mobile technologies used to address healthcare system challenges. These interventions, which we believe should be driven by relevant stakeholders, are broadly classified based on the primary users: clients, healthcare service providers, healthcare system managers, and cross-cutting data services. The model shows the various eHealth interventions that could support the measurement and improvement of UHC indicators.

The third component of the model is the UHC outcomes: quality healthcare services, access and coverage, and financial risk protection. The quality dimension of UHC, as shown in the model, is derived from IOM's definition of healthcare quality [22]. The dimensions of access, coverage, and financial risk protection are adapted from the Tanahashi model of healthcare service coverage [25] and Mehl's and Labrique's cascading model [26], which prioritizes mHealth strategies for attaining UHC.

FOUNDATIONAL DEVELOPMENT COMPONENTS

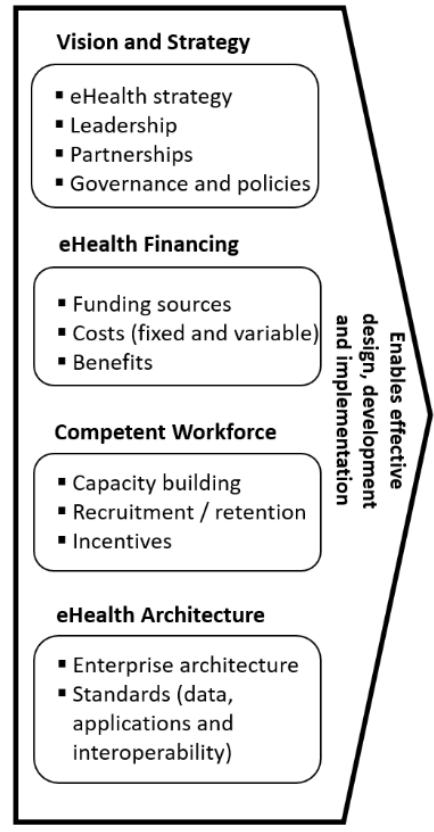

STAKEHOLDER-DRIVEN EHEALTH INTERVENTIONS

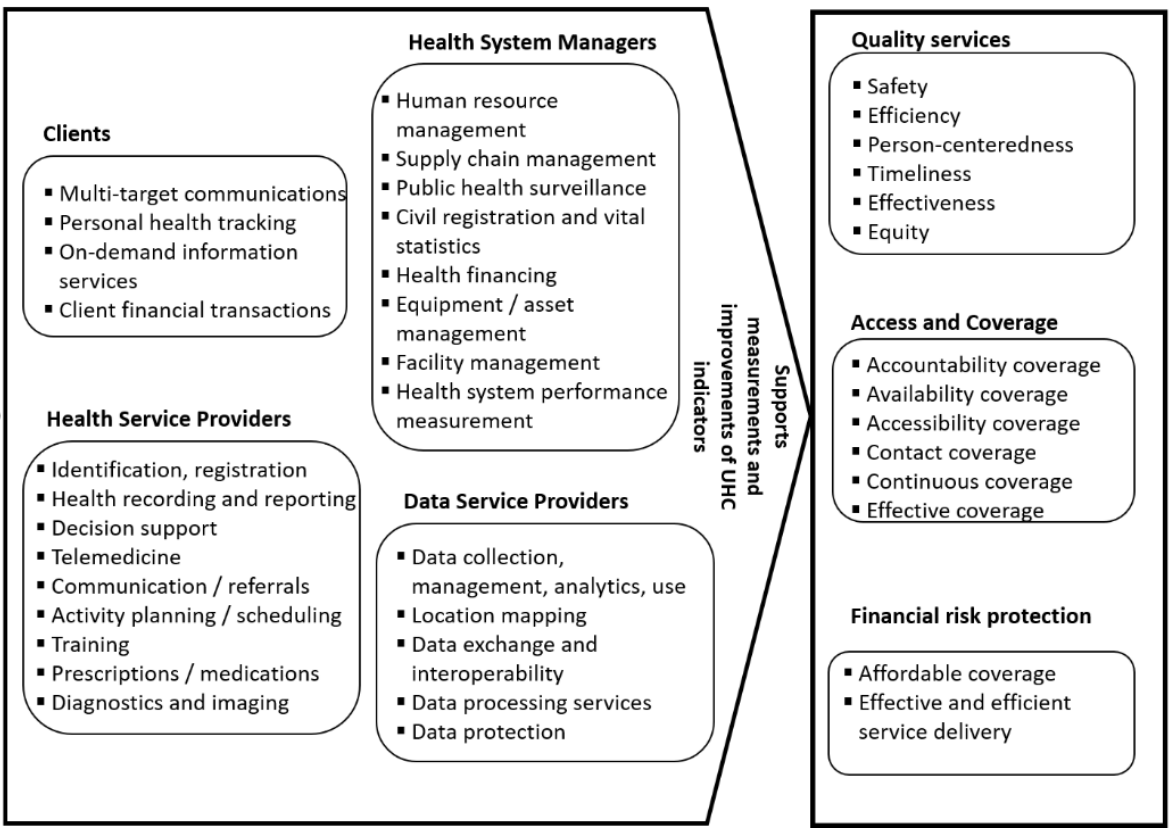

Figure 3: A conceptual strategic framework for leveraging eHealth to support universal health coverage

However, for eHealth interventions to deliver expected benefits, especially in sub-Saharan Africa, vision and strategy, adequate financing, a competent workforce, and a well-designed eHealth architecture are important components that should be considered.

Although this model was conceptualized for supporting UHC outcomes, it could apply to various disease domains (Figure 4). For instance, in the HIV domain, programmatic efforts are aimed at improving the quality of services, access, coverage, and financial risk protection for patients. 
Strengthening eHealth systems could enable the design, development, and implementation of eHealth interventions that support quality HIV care and services, thus reducing new infections and AIDS-related deaths. Similarly, eHealth interventions could lead to better coverage in terms of increased uptake in HIV testing and increased antiretroviral therapy coverage. For example, studies have shown that a common eHealth intervention in the HIV domain is using mobile technologies like text messaging and mobile applications to improve communication between patients and care providers, enhance appointment and medication adherence, improve uptake of testing, and support remote monitoring of patients [47-49]. In the case of financial risk protection, M-TIBA helps users save funds for their healthcare expenses. The application provides health insurance functionalities that allow users to receive funds from government, donor agencies, or family members; save funds; and spend saved funds only on medical treatment [35]. 


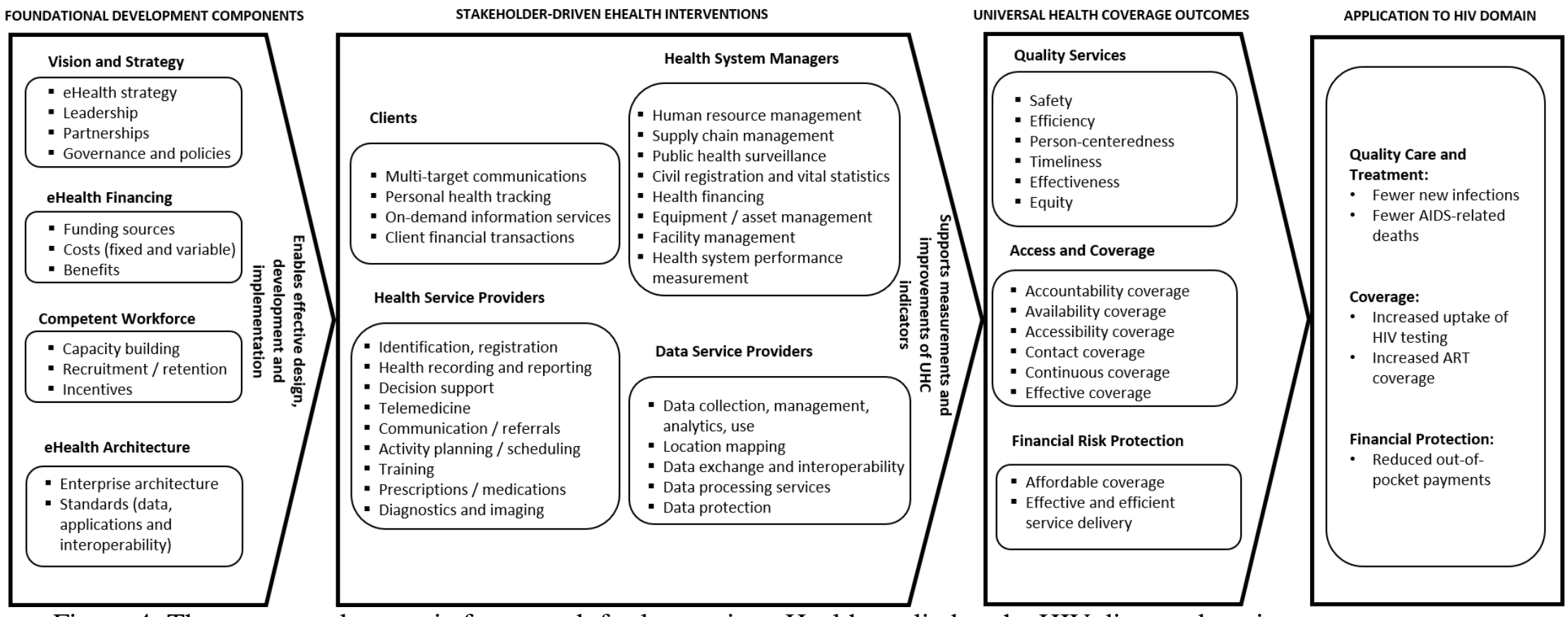

Figure 4: The conceptual strategic framework for leveraging eHealth applied to the HIV disease domain 


\section{Limitations}

The conceptual framework proposed in this paper is an adaptation of existing models. As such, it should be subjected to further refinements and empirical tests.

\section{Conclusion}

We propose a framework for strengthening eHealth systems to support the attainment of a country's UHC goals and to inform joint UHC and eHealth strategy development. Although the role of eHealth in supporting UHC objectives has been recognized, few publications have suggested appropriate strategies that can be used to implement effective eHealth systems. We posit that countries can strategically strengthen their eHealth system for supporting the UHC outcomes of quality healthcare, access, and financial risk protection via eHealth systems based on vision and strategy, adequate financing, a competent workforce, and a well-designed architecture. The proposed framework could aid countries in planning for supporting UHC with eHealth or in evaluating and identifying gaps in eHealth to achieve UHC. The framework can also be applied to other disease domains as part of ongoing efforts to strengthen healthcare systems. Further research exploring the direct contribution of eHealth interventions on UHC outcomes is recommended.

\section{Acknowledgments}

This publication has been supported by the President's Emergency Plan for AIDS Relief (PEPFAR) through the Centers for Disease Control and Prevention (CDC).

\section{Disclaimer}

The findings and conclusions in this paper are those of the authors and do not necessarily represent the official position of the Centers for Disease Control and Prevention (CDC).

\section{Conflicts of Interest:}

The authors have no conflicts of interest to declare.

\section{References}

1. World Health Organization. WHO called to return to the Declaration of Alma-Ata [Internet]. Soc. Determ. Heal. 2015 [cited 2020 Mar 4]. p. 1-2. Available from: https://www.who.int/social_determinants/tools/multimedia/alma_ata/en/.

2. Ghebreyesus TA. All roads lead to universal health coverage. Lancet Glob Heal [Internet]. 2017;5:e839-e840. Available from: http://linkinghub.elsevier.com/retrieve/pii/S2214109X17302954.

3. Bassett MT. 2006. Health for all in the 21st century. Am J Public Health. 96, 2089. PubMed https://doi.org/10.2105/AJPH.2006.102533 
4. World Health Organization. Arguing for Universal Health Coverage. World Heal. Organ. 2013.

5. World Health Organization. International Bank for Reconstruction and Development, WorldBank. Tracking Universal Health Coverage: 2017 Global Monitoring Report [Internet]. World Health Organization and International Bank for Reconstruction and Development / The World Bank; 2017. Available from:

http://apps.who.int/iris/bitstream/handle/10665/259817/9789241513555eng.pdf;jsessionid=C29E21005A5692511BE2B70BD2D3C941 ? sequence $=1$.

6. World Health Organization. UHC Service Coverage Index (SDG 3.8.1) [Internet]. Available from: https://www.who.int/data/gho/data/indicators/indicator-details/GHO/uhc-index-ofservice-coverage.

7. World Health Organization. Global diffusion of eHealth: Making universal health coverage achievable. Report of the third global survey on eHealth [Internet]. Geneva: World Health Organization; 2016. Available from:

https://www.who.int/goe/publications/global_diffusion/en/.

8. World Health Organization. Resolution WHA 58.28 eHealth. Fifty-eighth World Heal Assem Geneva, May 16 -25, 2005 Resolut Decis Annex [Internet]. Geneva; 2005. p. 121-123. Available from: http://www.who.int/healthacademy/news/en/.

9. Al-Shorbaji N. 2013. The World Health Assembly Resolutions on eHealth: eHealth in Support of Universal Health Coverage [Internet]. Methods Inf Med. 52, 463-66. http://www.thiemeconnect.de/DOI/DOI?10.1055/s-0038-1627062. PubMed https://doi.org/10.1055/s-0038$\underline{1627062}$

10. Etienne CF. 2014. eHealth: Harnessing technology on the road towards universal health coverage. Rev Panam Salud Publica. 35, 320-22. PubMed

11. Hussein R. 2015. A Review of Realizing the Universal Health Coverage (UHC) Goals by 2030: Part 2- What is the Role of eHealth and Technology? J Med Syst. •••, 72. PubMed https://doi.org/10.1007/s10916-015-0255-x

12. Ojo AI. 2018. mHealth Interventions in South Africa: A Review. SAGE Open. $\cdots, 8$. https://doi.org/10.1177/2158244018767223

13. Ingun $\mathrm{P}$, Streveler $\mathrm{D}$, Brown $\mathrm{K}$, et al. The role of information system in achieving universal health coverage [Internet]. 2010. Available from: http://www.who.int/healthsystems/topics/financing/healthreport/ICTTBNo10.pdf.

14. Sarbadhikari SN. 2013. The role of Public Health Informatics in providing Universal Health coverage. Int J Med Sci Public Health. 2, 162-63.

15. Labrique A, Vasudevan L, Mehl G, et al. 2018. Digital Health and Health Systems of the Future. Glob Health Sci Pract. 6, S1-4. PubMed https://doi.org/10.9745/GHSP-D-18-00342 
16. Asamoah-Odei E, Kebede D, Zielinski C, et al. 2011. Leveraging eHealth to improve national health systems in the African Region. Afr Health Monit. (March), 46-52.

17. Omotosho A, Ayegba P, Emuoyibofarhe J, et al. 2019. Current State of ICT in Healthcare Delivery in Developing Countries. Int $J$ Online Biomed Eng. 15, 91. https://doi.org/10.3991/ijoe.v15i08.10294

18. World Health Organization. WHO guideline: recommendations on digital interventions for health system strengthening. Geneva: World Health Organization; 2019.

19. Buntin MB, Jain SH, Blumenthal D. 2010. Health information technology: Laying the infrastructure for national health reform. Health Aff (Millwood). 29, 1214-19. PubMed https://doi.org/10.1377/hlthaff.2010.0503

20. World Health Organization. Classification of digital health interventions v1.0: a shared language to describe the uses of digital technology for health [Internet]. Geneva; 2018. Available from: https://apps.who.int/iris/handle/10665/260480.

21. National Academies of Sciences, Engineering, and Medicine. Crossing the Global Quality Chasm [Internet]. Crossing Glob. Qual. Chasm. Washington, D.C.: National Academies Press; 2018. Available from: https://doi.org/10.17226/25152.

22. Lilly CM, Zubrow MT, Kempner KM, et al. 2014. Critical Care telemedicine: Evolution and state of the art. Crit Care Med. 42, 2429-36. $\underline{\text { PubMed }}$ https://doi.org/10.1097/CCM.0000000000000539

23. Dharmar M, Kuppermann N, Romano PS, et al. 2013. Telemedicine consultations and medication errors in rural emergency departments. Pediatrics. 132, 1090-97. PubMed https://doi.org/10.1542/peds.2013-1374

24. Tanahashi T. 1978. Health service coverage and its evaluation [Internet]. Bull World Health Organ. 56, 295-303.

http://www.ncbi.nlm.nih.gov/pubmed/96953\%0Ahttp://www.pubmedcentral.nih.gov/arti clerender.fcgi?artid=PMC2395571. PubMed

25. Mehl G, Labrique A. Prioritizing integrated mHealth strategies for universal health coverage. Science (80-) [Internet]. 2014;345:1284-1287. Available from: http://www.sciencemag.org/cgi/doi/10.1126/science.1258926.

26. Odei-Lartey EO, Boateng D, Danso S, et al. 2016. The application of a biometric identification technique for linking community and hospital data in rural Ghana. Glob Health Action. 9, 17. PubMed https://doi.org/10.3402/gha.v9.29854

27. Forcillo J, Watkins DA, Brooks A, et al. 2019. Making cardiac surgery feasible in African countries: Experience from Namibia, Uganda, and Zambia. J Thorac Cardiovasc Surg. 158, 1384-93. PubMed https://doi.org/10.1016/j.jtcvs.2019.01.054 
28. Faye O, Bagayoko C, Dicko A, et al. 2018. A Teledermatology Pilot Programme for the Management of Skin Diseases in Primary Health Care Centres: Experiences from a ResourceLimited Country (Mali, West Africa). Trop Med Infect Dis. 3, 88. PubMed https://doi.org/10.3390/tropicalmed3030088

29. Leone M, Corsi FM, Ferrari F, et al. 2018. Teleneurology in sub-Saharan Africa: Experience from a long lasting HIV/AIDS health program (DREAM). J Neurol Sci. 391, 109-11. PubMed https://doi.org/10.1016/j.jns.2018.06.013

30. Were V, Jere E, Lanyo K, et al. 2019. Success of a South-South collaboration on Human Resources Information Systems (HRIS) in health: A case of Kenya and Zambia HRIS collaboration. Hum Resour Health. 17, 6-11. PubMed https://doi.org/10.1186/s12960-019$\underline{0342-\mathrm{Z}}$

31. Shieshia M, Noel M, Andersson S, et al. 2014. Strengthening community health supply chain performance through an integrated approach: Using mHealth technology and multilevel teams in Malawi. J Glob Health., 4. PubMed https://doi.org/10.7189/jogh.04.020406

32. John-Stewart G. 2018. eHealth and Prevention of Mother-to-Child Transmission of HIV . Curr HIV/AIDS Rep. 15, 350-57. PubMed https://doi.org/10.1007/s11904-018-0408-x

33. Yau M, Timmerman V, Zwarenstein M, et al. e-PC101: an electronic clinical decision support tool developed in South Africa for primary care in low-income and middle-income countries. BMJ Glob Heal [Internet]. 2019;3:e001093. Available from:

http://gh.bmj.com/lookup/doi/10.1136/bmjgh-2018-001093.

34. Pore M, Arnold AL, Mugambi P, et al. 2018. A qualitative evaluation of a decision support system for district-level disease surveillance in Sierra Leone. Stud Health Technol Inform. 247, 451-55. PubMed

35. Meessen B. The Role of Digital Strategies in Financing Health Care for Universal Health Coverage in Low- and Middle-Income Countries. Glob Heal Sci Pract [Internet]. 2018;6:S29S40. Available from: http://www.ghspjournal.org/lookup/doi/10.9745/GHSP-D-18-00271.

36. Bassi J, Lau F. 2013. Measuring value for money: A scoping review on economic evaluation of health information systems. $J$ Am Med Inform Assoc. 20, 792-801. PubMed https://doi.org/10.1136/amiajnl-2012-001422

37. Brand B, LaVenture M, Lipshutz JA, et al. 2018. The Information Imperative for Public Health: A Call to Action to Become Informatics-Savvy. J Public Health Manag Pract [Internet]. 24, 586-89. http://insights.ovid.com/crossref?an=00124784-201811000-00014. PubMed https://doi.org/10.1097/PHH.0000000000000892

38. Adeloye D, Adigun T, Misra S, et al. 2017. Assessing the Coverage of E-Health Services in Sub-Saharan Africa [Internet]. Methods Inf Med. 56, 189-99. http://www.thiemeconnect.de/DOI/DOI?10.3414/ME16-05-0012. PubMed https://doi.org/10.3414/ME16-05$\underline{0012}$ 
39. Kiberu VM, Mars M, Scott RE. 2017. Barriers and opportunities to implementation of sustainable e-Health programmes in Uganda: A literature review. Afr J Prim Health Care Fam Med. 9, 8. PubMed https://doi.org/10.4102/phcfm.v9i1.1277

40. Scott RE, Mars M. 2013. Principles and framework for eHealth strategy development. J Med Internet Res. 15, 1-14. PubMed https://doi.org/10.2196/jmir.2250

41. Ojo AI. Repositioning health information management practice in Nigeria: Suggestions for Africa. Heal Inf Manag J [Internet]. 2018;47:140-144. Available from: http://journals.sagepub.com/doi/10.1177/1833358317732008.

42. Jones T, Stroetmann K, Dobrev A, et al. 2011. eHealth for African Countries - Sustainable Strategies. IST-Africa. 2011, 1-11.

43. Abu Taher S, Uddin MK, Tsuji M. Financing eHealth: Tsuji-Akematsu model revisited. 22nd Bienn Conf Int Telecommun Soc "Beyond boundaries Challenges business, policy Soc. Seoul: International Telecommunications Society; 2018.

44. Ogoe HA, Asamani JA, Hochheiser H, et al. 2018. Assessing Ghana's eHealth workforce: implications for planning and training [Internet]. Hum Resour Health. 16, 65. http://ovidsp.ovid.com/ovidweb.cgi?T=JS\&PAGE=reference \&D=emexa\&NEWS=N\&AN= 625217977. PubMed https://doi.org/10.1186/s12960-018-0330-8

45. Frenk J, Chen L, Bhutta ZA, et al. 2010. Health professionals for a new century: transforming education to strengthen health systems in an interdependent world [Internet]. Lancet. 376, 1923-58. https://linkinghub.elsevier.com/retrieve/pii/S0140673610618545. PubMed https://doi.org/10.1016/S0140-6736(10)61854-5

46. Higman S, Dwivedi V, Nsaghurwe A, et al. 2019. Designing interoperable health information systems using Enterprise Architecture approach in resource-limited countries: A literature review. Int J Health Plann Manage. 34, e85-99. PubMed https://doi.org/10.1002/hpm.2634

47. van den Berk GEL, Leoni MC, Behrens GMN, et al. 2020. Improving HIV-related care through eHealth [Internet]. Lancet HIV. 7, e8-10. doi:https://doi.org/10.1016/S2352$\underline{3018(19) 30348-0 .}$. PubMed

48. Purnomo J, Coote K, Mao L, et al. 2018. Using eHealth to engage and retain priority populations in the HIV treatment and care cascade in the Asia-Pacific region: A systematic review of literature. BMC Infect Dis. 18, 1-16. PubMed https://doi.org/10.1186/s12879-018$\underline{2972-5}$

49. Henny KD, Wilkes AL, McDonald CM, et al. 2018. A Rapid Review of eHealth Interventions Addressing the Continuum of HIV Care (2007-2017). AIDS Behav. 22, 43-63. PubMed https://doi.org/10.1007/s10461-017-1923-2 